\title{
BMJ Open Young adolescent girls are at high risk for adverse pregnancy outcomes in sub-Saharan Africa: an observational multicountry study
}

Ghyslain Mombo-Ngoma, ${ }^{1,2,3,4,5}$ Jean Rodolphe Mackanga, ${ }^{1,2,3}$ Raquel González, ${ }^{6,7}$ Smaila Ouedraogo, ${ }^{8,9}$ Mwaka A Kakolwa, ${ }^{10}$ Rella Zoleko Manego, ${ }^{2,11}$ Arti Basra, ${ }^{1,2,3}$ María Rupérez, ${ }^{6,7}$ Michel Cot, ${ }^{9}$ Abdunoor M Kabanywany, ${ }^{10}$ Pierre-Blaise Matsiegui, ${ }^{11}$ Seldiji T Agnandji, ${ }^{1,2,3}$ Anifa Vala, ${ }^{6}$ Achille Massougbodji, ${ }^{8}$ Salim Abdulla, ${ }^{10}$ Ayôla A Adegnika, ${ }^{1,2,3,5}$ Esperança Sevene, ${ }^{6,7}$ Eusebio Macete, ${ }^{6}$ Maria Yazdanbakhsh, ${ }^{5}$ Peter G Kremsner, ${ }^{1,2,3}$ John J Aponte, ${ }^{7}$ Clara Menéndez, ${ }^{7}$ Michael Ramharter ${ }^{1,2,3,12}$

To cite: Mombo-Ngoma G, Mackanga JR, González R, et al. Young adolescent girls are at high risk for adverse pregnancy outcomes in sub-Saharan Africa: an observational multicountry study. BMJ Open 2016;6: e011783. doi:10.1136/ bmjopen-2016-011783

- Prepublication history and additional material is available. To view please visit the journal (http://dx.doi.org/ 10.1136/bmjopen-2016011783).

Received 6 March 2016 Revised 12 April 2016 Accepted 14 April 2016

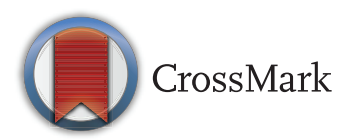

For numbered affiliations see end of article.

Correspondence to Dr Michael Ramharter; michael.ramharter@medizin. uni-tuebingen.de

\section{ABSTRACT}

Objectives: One of Africa's most important challenges is to improve maternal and neonatal health. The identification of groups at highest risk for adverse pregnancy outcomes is important for developing and implementing targeted prevention programmes. This study assessed whether young adolescent girls constitute a group at increased risk for adverse birth outcomes among pregnant women in sub-Saharan Africa.

Setting: Data were collected prospectively as part of a large randomised controlled clinical trial evaluating intermittent preventive treatment of malaria in pregnancy (NCT00811421_Clinical Trials.gov), conducted between September 2009 and December 2013 in Benin, Gabon, Mozambique and Tanzania.

Participants: Of 4749 participants, pregnancy outcomes were collected for 4388 deliveries with 4183 live births including 83 multiple gestations. Of 4100 mothers with a singleton live birth delivery, $24 \%(975 / 4100)$ were adolescents ( $\leq 19$ years of age) and $6 \%(248 / 4100)$ were aged $\leq 16$ years.

Primary and secondary outcome measures: Primary outcomes of this predefined analysis were preterm delivery and low birth weight.

Results: The overall prevalence of low birthweight infants and preterm delivery was $10 \%$ (371/3851) and $4 \%(159 / 3862)$, respectively. Mothers aged $\leq 16$ years showed higher risk for the delivery of a low birthweight infant (OR: $1.96 ; 95 \% \mathrm{Cl} 1.35$ to 2.83). Similarly, preterm delivery was associated with young maternal age ( $\leq 16$ years; OR: $2.62 ; 95 \% \mathrm{Cl}$ 1.59 to 4.30 ). In a subanalysis restricted to primiparous women: preterm delivery, OR 4.28; $95 \%$ $\mathrm{Cl} 2.05$ to 8.93 ; low birth weight, OR: $1.29 ; 95 \% \mathrm{Cl}$ 0.82 to 2.01 .

Conclusions: Young maternal age increases the risk for adverse pregnancy outcomes and it is a stronger predictor for low birth weight and preterm delivery

\section{Strengths and limitations of this study}

- Prospective design.

- Highly standardised data collection and follow-up of participants in diverse African sub-regions.

- The setting of a randomised controlled trial ensured high coverage of standard antenatal care including vitamin and micronutrient supplementation, insecticide treated bed nets and availability of healthcare without access barriers.

- Inclusion of only HIV-negative pregnant women constituting a limitation for external validity.

- The interplay between risk factors for adverse pregnancy outcome is complex and residual confounding may not be completely ruled out.

than other established risk factors in sub-Saharan Africa. This finding highlights the need to improve adolescent reproductive health in sub-Saharan Africa.

Trial registration number: NCT00811421;

Post-results.

In summary, this large prospective clinical trial provides conclusive evidence that young adolescent girls are at considerably higher risk for premature and low birth weight deliveries in sub-Saharan Africa. From a public health perspective, young adolescent pregnant women constitute an easily identifiable patient population amenable to targeted antenatal care programmes. Development of tailored antenatal care and facilitation of early attendance of antenatal care by young adolescent girls should therefore become a priority to improve adolescent health in sub-Saharan Africa. 


\section{INTRODUCTION}

Improving maternal and neonatal health is among Africa's most urgent challenges in public health. ${ }^{12}$ The excess rate of maternal and neonatal morbidity and mortality derives from multiple causes in sub-Saharan Africa including endemic infectious diseases, malnutrition and micronutrient deficiencies, gynaecological and obstetric complications with suboptimal antenatal and perinatal as well as often inadequate postnatal care caused by a lack of adequate financial and logistic resources. ${ }^{2-4}$ Targeted public health interventions such as intermittent preventive treatment of malaria in pregnancy (IPTp), vitamin and micronutrient supplementation, provision of long-lasting insecticide-treated nets (LLITNs), prevention of mother-to-child HIV transmission and improved frequency and quality of gynaeco-obstetric healthcare are the cornerstones of current strategies to reduce adverse pregnancy outcomes in Africa. ${ }^{5-8}$

It is well known that the risk for adverse pregnancy outcomes is distributed highly unevenly within populations. Further reductions of maternal and neonatal morbidity and mortality can therefore be achieved most efficiently by the identification of those individuals most at risk. ${ }^{9}$

With $44 \%$ of its population aged below 15 years, sub-Saharan Africa is the youngest region in the world. ${ }^{10}$ However, from a medical and public health perspective, adolescence is a largely neglected period of life. Few epidemiological studies in Africa focus on this period of life and targeted public health programmes addressing the most important challenges for adolescent health and well-being are lacking.

Sexual and reproductive health is arguably among the most vital health challenges for adolescents in sub-Saharan Africa. ${ }^{11}$ Although some regions in sub-Saharan Africa are characterised by a high proportion of very young pregnant women, it is currently unclear whether these young girls benefit equally from established routine antenatal care programmes or whether more targeted programmes would be necessary to address specific needs of this vulnerable group of pregnant women.

On the basis of previous retrospective studies, this study was designed to evaluate prospectively whether young maternal age may serve as an easily recognisable predictor for adverse pregnancy outcome in sub-Saharan Africa. This hypothesis was assessed in the context of a clinical trial with access to a package of free and high quality routine antenatal care, effective preventive treatment of malaria in pregnancy, and provision of LLITNs.

\section{MATERIALS AND METHODS}

Pregnant women and their offspring participated in a randomised controlled trial assessing alternative drugs for intermittent preventive treatment of malaria in pregnancy (MiPPAD; NCT00811421-Clinical Trials.gov). ${ }^{12}$ This study was conducted in four African countries between September 2009 and December 2013, involving regions from Western, Eastern, Central and Southern
sub-Saharan Africa. Pregnant women were recruited at their first antenatal visit if they were HIV-negative, presented with a gestational age below 28 weeks of gestation at their first antenatal care visit, and were willing to participate in the study and give birth in the study health facility. Exclusion criteria were a history of allergy to any of the study drugs or any other ongoing serious condition. All women received LLITNs and were randomly allocated to either standard sulfadoxine-pyrimethamine or mefloquine preventive treatment for malaria. Women were followed up until 1 month after delivery and infants were followed up until their first anniversary. All costs for antenatal and postnatal care and transport to respective health facilities were free of charge for participants.

Participants' baseline information was recorded at recruitment including maternal age, weight, height, mid-upper arm circumference (MUAC), date of last menstruation and gestational age by bimanual palpation, obstetrical history, syphilis test (rapid plasma reagin (RPR) testing), haemoglobin level, literacy as ability to read and/or write. Body mass index (BMI) was categorised for further statistical analysis using predefined threshold levels by the WHO (underweight: $\mathrm{BMI}<18.5$; normal weight: BMI 18.5-24.9; overweight: BMI 25.029.9; obese: BMI $\geq 30.0$ ). The cut-off for the MUAC was defined as $240 \mathrm{~mm}$ according to the UNICEF recommendations. ${ }^{13}$

Gestational age, birth outcome and characteristics of delivery were recorded at delivery and haemoglobin levels were assessed from finger-prick or venous blood using the HemoCue device (http://www.eurotrol.com). Infection with Plasmodium falciparum at delivery was defined as the detection of malaria parasites in peripheral blood or placental samples collected at delivery. Parasitological assessments were performed from peripheral and cord blood, as well as from placenta by thick and thin smears and impression smears, respectively.

Maternal age was calculated from the date of birth recorded in an official health booklet at enrolment or in case of lack of documentation by self-reported date of birth. Adolescence was defined as per the WHO definition, 'young individuals between the ages of 10 and 19 years'. ${ }^{14}$ Maternal age was divided into four categories including young adolescents aged $\leq 16$ years, adolescents aged 17-19 years, adults aged 20-30 years and those aged 31 years and above. The sample size of the data set supported the use of such stratification in all analyses.

The main delivery end points for this analysis were the proportions of low birthweight infants and preterm delivery and secondarily the proportion of maternal anaemia at delivery. Low birth weight was defined as $<2500 \mathrm{~g}$ and was measured within the 24 hours after birth using digital infant scales. Scales were calibrated weekly and quality controlled. In case of home deliveries or other reasons for delayed measurement of birth weight, data were imputed using a previously published regression model. ${ }^{15}$ Premature delivery was defined as delivery before 37 weeks of gestation. Gestational age at 
recruitment was determined from the measure of the symphysis-fundus height by bimanual palpation at the first antenatal visit. At delivery, gestational age was assessed by the Ballard Score. ${ }^{16}$ Anaemia was defined as haemoglobin level $<11 \mathrm{~g} / \mathrm{dL}$.

\section{Statistical analysis, conceptual framework and causal diagram}

Several factors including socioeconomic disadvantage, low BMI and MUAC, primiparity and non-attendance of antenatal care visits have been described as risk factors associated with poor birth outcomes. These factors could therefore potentially confound any observed association between young adolescent pregnancy and adverse pregnancy outcome and were therefore included in statistical analysis. A simplified illustration of the conceptual framework built up to guide this analysis is shown in figure 1.

Statistical analyses were restricted to singleton births and were conducted using Stata IC/V.13.1 for Windows (StataCorpLp, College station, Texas, USA). The distribution of baseline characteristics was described and compared according to maternal age groups. Univariate analysis was performed to assess the crude association between maternal age and low birth weight or preterm delivery. In addition, other variables associated with higher odds for low birth weight, prematurity and maternal anaemia were identified. Variables associated with adverse birth outcomes and maternal age were considered potential confounders. In a further step, logistic regression models adjusting for potential confounders or other covariables were constructed according to their effect on the point estimate rather than providing $p$ values. As a guide, the change in the point estimate was considered significant if equal to or above $10 \%$-an arbitrary cut-off level. We performed stepwise removal of variables in the absence of evidence for an effect on the point estimate. ${ }^{17}$ However, forced variables (country, treatment arm) were defined and kept in the final model whatever their effect on the point estimate was as these were inherent to the study design. The final model evaluated the adjusted ORs of adverse birth outcome in the different age groups. For the analysis of preterm delivery, data from Tanzania were excluded because of a systematic error in the assessment of gestational age by the Ballard score at this study site.

\section{Ethical considerations}

All women participating in the study had signed a written informed consent form before any study related procedure was performed. The study was conducted according to the International Conference for harmonization of Good Clinical Practice (ICH-GCP) principles and the Declaration of Helsinki.

\section{RESULTS}

A total of 14179 pregnant women attending antenatal clinics in Benin, Gabon, Mozambique and Tanzania were screened between September 2009 and December

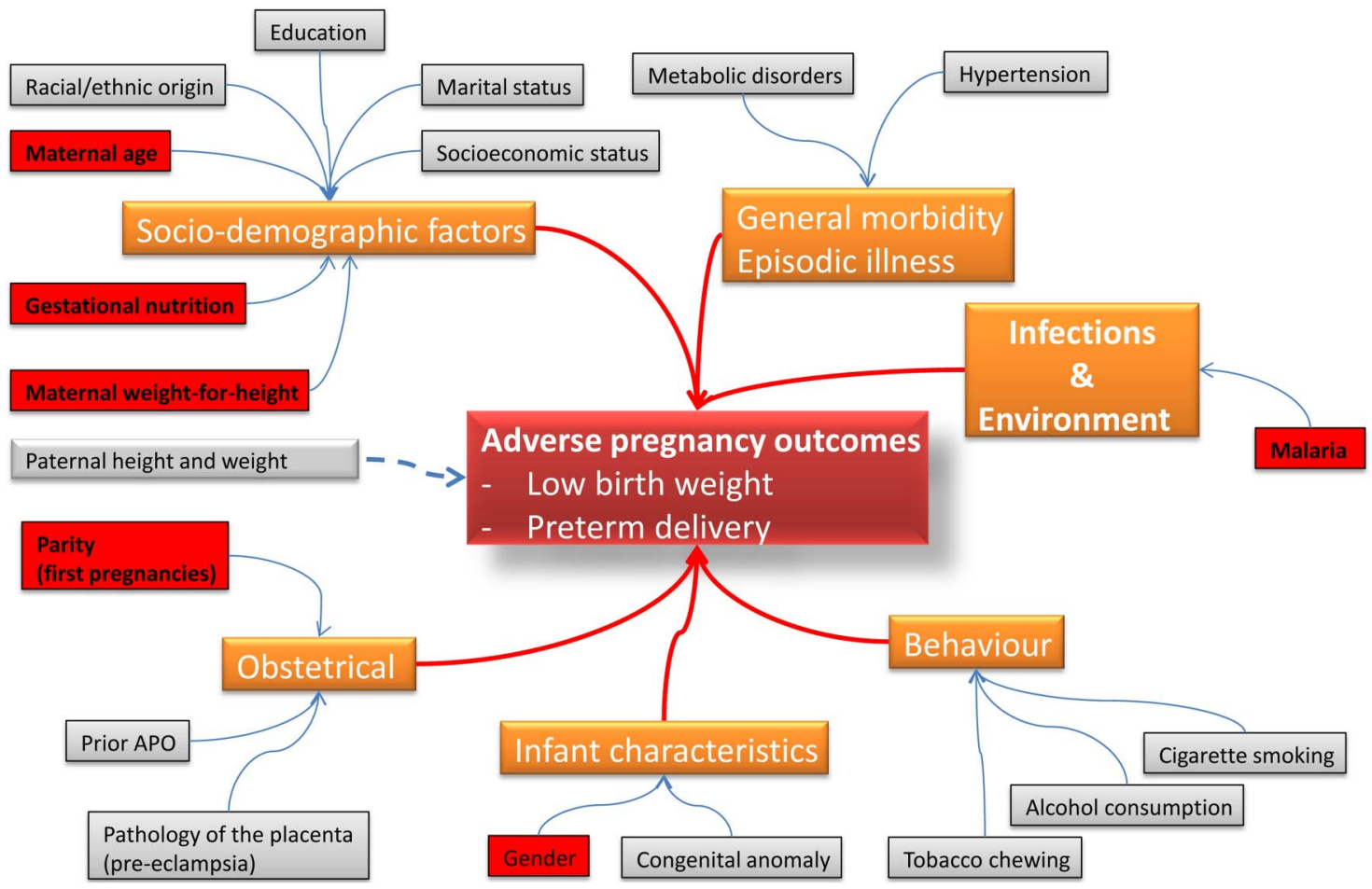

Figure 1 Conceptual framework of risk factors of adverse pregnancy outcome (APO). Orange boxes are categories of risk factors of Adverse Pregnancy Outcome (APO) have been categorised (orange boxes). The red boxes are the risk factors discussed throughout this paper. The grey boxes represent known risk factors of APO which were not addressed in this paper. 
2012 for recruitment to the MiPPAD trial and 4749 were randomised at the four study sites. Among those, 361 $(7.6 \%)$ were lost or withdrawn before delivery, with 79 (22\%) adolescents, $237(66 \%)$ women aged between 20 and 30 years and $45(12 \%)$ women aged 31 years or more. There was no significant difference observed in baseline characteristics between the women lost or withdrawn from the study and those considered in the analysis for this study (see online supplementary figure S1). Of the 4388 recorded deliveries, 4183 were living births including 83 multiple gestations. Mother-child pairs of 4100 singleton infants constitute the population of the primary analysis of this report. Details of the participant flow are depicted in figure 2.

Among 4100 pregnant participants with a singleton live birth, $24 \%(975 / 4100)$ were adolescents with $6 \%$ $(248 / 4100)$ aged $\leq 16$ years. There was a significant difference in the proportion of adolescent mothers between countries (table 1). Significant differences between maternal age groups were identified according to the period of the first antenatal visit as adolescent women attended earlier compared to other age groups. Differences were also apparent for parity, nutritional status, literacy, baseline anaemia and syphilis infection at first presentation to antenatal care clinics (table 1). Owing to the randomisation, there was no difference in the allocation to respective intermittent preventive treatment groups (table 1).

Among singleton live births, the overall proportion of low birthweight infants and preterm delivery was $10 \%$ $(371 / 3851)$ and $4 \%$ (159/3862), respectively. The proportion of women with maternal anaemia at delivery was $41 \%(1586 / 3884)$.

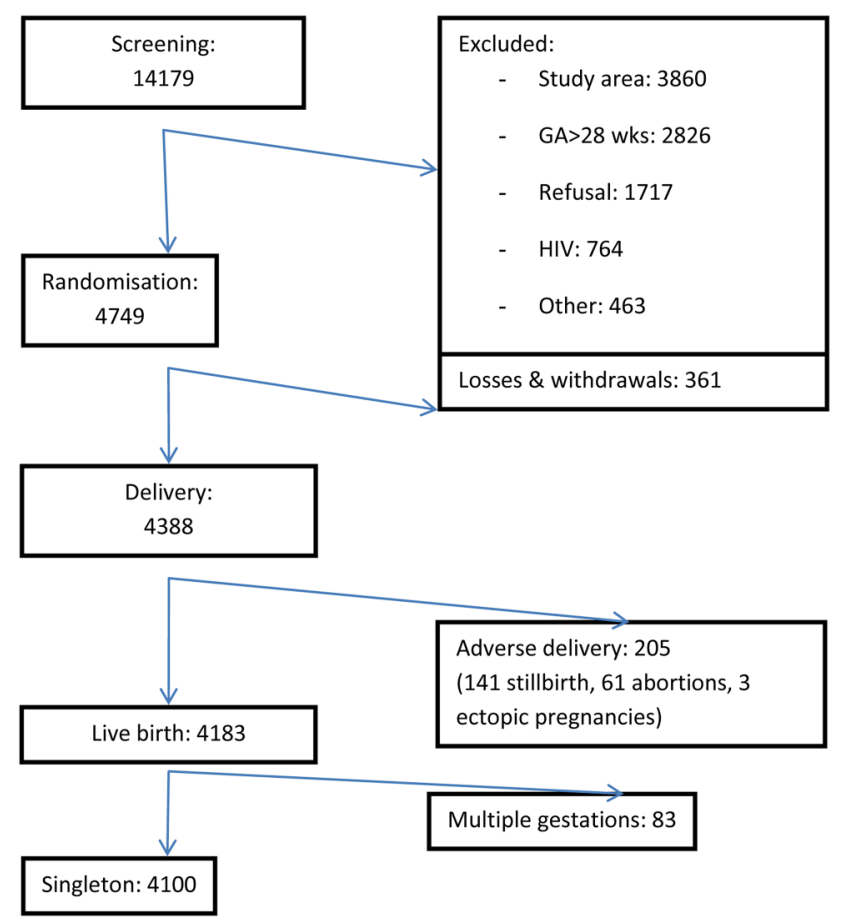

Figure 2 Participants flow. GA, gestational age.
At delivery, very young maternal age $(\leq 16$ years) was the variable with the highest risk for the delivery of a low birthweight infant, $16 \%(39 / 248)$ compared to adult mothers aged 20-30 years, 9\% (207/2376) (crude OR: $1.96 ; 95 \%$ CI 1.35 to 2.83 ) (table 2). Other factors significantly associated with increased risk for low birth weight were country, trimester of first antenatal visit, parity, BMI and MUAC (table 2). Similarly, preterm birth was most closely associated with very young maternal age $\leq 16$ years (OR: 2.62; 95\% CI 1.59 to 2.13). Other factors significantly associated with preterm birth were country, BMI and literacy (table 2).

Multivariable risk factors analysis was performed to assess confounding and potential causal relationships of covariables. After controlling for country, trimester of first antenatal visit, treatment group and infant gender, there remained strong evidence for increased odds for low birth weight in very young adolescent mothers ( $\leq 16$ years), OR 2.06 (1.37 to 3.12 ). However, this association was weaker when controlling for BMI, parity, literacy, plasmodium infection and MUAC (table 3). Conversely, preterm delivery remained significantly associated with young maternal age in multivariate analysis, OR 2.16 (1.10 to 4.24) (table 3). Maternal anaemia was not associated with respective age groups (see online supplementary tables S1 and S2).

A subanalysis restricted to primiparous women was performed to control for parity, which is a wellestablished risk factor for adverse pregnancy outcome and which inherently is associated with maternal age. This restricted analysis demonstrated that very young maternal age was associated with higher risk for adverse pregnancy outcome (preterm delivery: OR 4.28; 95\% CI 2.05 to 8.93 ; low birth weight: OR: 1.29 ; $95 \%$ CI 0.82 to 2.01) (see online supplementary table S3).

\section{DISCUSSION}

The identification of high-risk groups among pregnant women is of high priority to develop cost-effective interventions to further reduce maternal and neonatal mortality in sub-Saharan Africa. In this prospective multinational cohort of pregnant women in sub-Saharan Africa, young maternal age was the strongest predictor for adverse pregnancy outcome. Very young mothers were more likely than their older peers to deliver prematurely or a low birthweight infant-two of the key surrogate markers for adverse pregnancy outcome and infant mortality. ${ }^{9} 1819$

Our finding is supported by previous reports from other geographical and socioeconomic settings demonstrating a higher than normal risk for teenagers in pregnancy. ${ }^{20}$ Several hypotheses have been previously proposed to explain the higher risk for adverse pregnancy outcomes in this group of pregnant women including social and economic disadvantage, behavioural factors increasing the risk for adverse pregnancy outcome and biological immaturity of the mother. ${ }^{22}$ In 
Table 1 Distribution of baseline characteristics by maternal age group

\begin{tabular}{|c|c|c|c|c|c|c|}
\hline & \multirow[b]{2}{*}{$\begin{array}{l}\text { Overall } \\
N=4100\end{array}$} & \multicolumn{4}{|c|}{ Maternal age (years) } & \multirow[b]{2}{*}{$\begin{array}{l}\text { p Value } \\
\left(\chi^{2} \text { test }\right.\end{array}$} \\
\hline & & $\begin{array}{l}14-16 \\
(n=248)\end{array}$ & $\begin{array}{l}17-19 \\
(n=727)\end{array}$ & $\begin{array}{l}20-30 \\
(n=2400)\end{array}$ & $\begin{array}{l}31+ \\
(n=725)\end{array}$ & \\
\hline \multicolumn{7}{|l|}{ Country } \\
\hline Benin & 1027 & $5(0.5)$ & $98(9.5)$ & $754(73.4)$ & $170(16.6)$ & $<0.001$ \\
\hline Gabon & 953 & $79(8.3)$ & $221(23.2)$ & $462(48.5)$ & $191(20.0)$ & \\
\hline Mozambique & 1098 & $157(14.3)$ & 277 (25.2) & 489 (44.5) & 175 (15.9) & \\
\hline Tanzania & 1022 & $7(0.7)$ & $131(12.8)$ & $695(68.0)$ & 189 (18.5) & \\
\hline \multicolumn{7}{|l|}{ First ANC visit } \\
\hline First trimester & 298 & $22(8.9)$ & $66(9.1)$ & $161(6.7)$ & $49(6.8)$ & 0.005 \\
\hline Second trimester & 2899 & $186(75.0)$ & 522 (71.9) & 1667 (69.5) & $524(72.2)$ & \\
\hline Third trimester & 902 & $40(16.1)$ & $138(19.0)$ & 572 (23.8) & $152(21.0)$ & \\
\hline \multicolumn{7}{|l|}{ Parity } \\
\hline Nulliparous & 1328 & 239 (96.4) & $548(75.4)$ & $522(21.7)$ & $19(2.6)$ & $<0.001$ \\
\hline Multiparous & 2772 & $9(3.6)$ & 179 (24.6) & 1878 (78.2) & 706 (97.4) & \\
\hline \multicolumn{7}{|l|}{$\mathrm{BMI}$} \\
\hline Underweight & 493 & $30(12.1)$ & $101(13.9)$ & 306 (12.8) & $56(7.7)$ & $<0.001$ \\
\hline Normal & 2689 & $184(74.2)$ & $548(75.6)$ & $1572(65.5)$ & $385(53.1)$ & \\
\hline Overweight/obese & 915 & $34(13.7)$ & 76 (10.5) & $521(21.7)$ & $284(39.2)$ & \\
\hline \multicolumn{7}{|l|}{$\operatorname{MUAC}(\mathrm{mm})$} \\
\hline$\geq 240$ & 3312 & $171(68.9)$ & $524(72.4)$ & $1964(82.1)$ & $653(90.1)$ & $<0.001$ \\
\hline$<240$ & 776 & 77 (31.1) & $200(27.6)$ & 427 (17.9) & 72 (9.9) & \\
\hline \multicolumn{7}{|l|}{ Literacy } \\
\hline Literate & 2846 & $220(88.7)$ & $626(86.1)$ & $1527(63.6)$ & $473(65.2)$ & $<0.001$ \\
\hline Illiterate & 1254 & 28 (11.3) & 101 (13.9) & $873(36.4)$ & 252 (34.8) & \\
\hline \multicolumn{7}{|l|}{ Baseline anaemia } \\
\hline No & 1656 & $94(37.9)$ & $261(36.0)$ & 985 (41.2) & $316(43.8)$ & 0.001 \\
\hline Yes & 2430 & $154(62.0)$ & $463(64.0)$ & $1408(58.8)$ & 405 (56.2) & \\
\hline \multicolumn{7}{|l|}{ Syphilis test } \\
\hline Negative & 3961 & $246(100)$ & 705 (98.7) & 2319 (98.8) & 691 (97.2) & 0.001 \\
\hline Positive & 57 & $0(0)$ & $9(1.3)$ & $28(1.2)$ & $20(2.8)$ & \\
\hline \multicolumn{7}{|l|}{ IPTp } \\
\hline$M Q$ & 2720 & $166(66.9)$ & 479 (65.9) & 1599 (66.6) & $476(65.7)$ & 0.95 \\
\hline $\mathrm{SP}$ & 1380 & $82(33.1)$ & $248(34.1)$ & 801 (33.4) & 249 (34.3) & \\
\hline
\end{tabular}

this analysis, there was no difference in literacy, nutritional status or syphilis prevalence between young and older pregnant women. In addition antenatal care was provided uniformly during the conduct of the clinical trial excluding differences in healthcare-related effects. Importantly, this study was not designed to investigate underlying causes for adverse pregnancy outcome. Conversely, the aim of this study was to assess whether young maternal age may be used as a simple predictive marker for a population at high risk for adverse pregnancy outcome in sub-Saharan Africa and to allow for future targeted interventions in this at-risk group.

Interestingly, young maternal age showed a stronger association with adverse pregnancy outcome than other established risk factors including parity or malaria infection in univariate analysis. In regions of high malaria transmission, it is estimated that plasmodial infections may cause about $19 \%$ of low birth weight deliveries. ${ }^{23}$ Malaria infection was highly prevalent in this study in Gabon and Benin, and these two countries concordantly had the highest incidence of low birth weight. It is also well established that the impact of malaria in pregnancy is highest in primigravid women. ${ }^{24}$ Whereas this was similarly observed in this cohort of pregnant women, an analysis restricted to primigravid women still demonstrated an excess risk for low birth weight and preterm delivery in young adolescent mothers stressing the importance of young maternal age as a risk factor. In addition, multivariable analysis indicated that young maternal age is significantly associated with premature delivery. These data unequivocally demonstrate that young maternal age constitutes a risk factor for adverse birth outcome. On the basis of these data, it is evident that young adolescent girls are a readily identifiable at-risk population in sub-Saharan Africa.

Young adolescent pregnancy rates differ considerably between countries. In this study, high rates were observed in Gabon and Mozambique, and lower rates were found in Benin and Tanzania. This difference is mainly explained by sociocultural and religious determinants of societies. This fact also highlights that young 
Table 2 Incidence of low birth weight and preterm birth and univariate analysis of the risk factors

\begin{tabular}{|c|c|c|c|c|c|c|c|c|}
\hline \multirow[b]{2}{*}{ Parameters } & \multicolumn{4}{|c|}{ Birth weight } & \multicolumn{4}{|c|}{ Preterm birth } \\
\hline & $\begin{array}{l}\text { Singleton } \\
\text { live } \\
\text { births, N }\end{array}$ & $\begin{array}{l}\text { LBW, n } \\
(\%)\end{array}$ & $\begin{array}{l}\text { Unadjusted OR } \\
(95 \% \mathrm{Cl})\end{array}$ & $\begin{array}{l}\text { p Value } \\
\text { (LRT) }\end{array}$ & $\begin{array}{l}\text { Singleton } \\
\text { live } \\
\text { births, N }\end{array}$ & $\begin{array}{l}\text { Preterm, } \\
\text { n (\%) }\end{array}$ & $\begin{array}{l}\text { Unadjusted OR } \\
(95 \% \mathrm{Cl})\end{array}$ & $\begin{array}{l}\mathbf{p} \\
\text { Value } \\
\text { (LRT) }\end{array}$ \\
\hline \multicolumn{9}{|c|}{ Maternal age (years) } \\
\hline $14-16$ & 248 & $39(15.7)$ & 1.96 (1.35 to 2.83$)$ & & 214 & $20(9.4)$ & 1.82 (1.09 to 3.03 ) & \\
\hline $17-19$ & 714 & $98(13.7)$ & 1.67 (1.29 to 2.15$)$ & $<0.001$ & 543 & $35(6.4)$ & $1.22(0.81$ to 1.83$)$ & 0.15 \\
\hline 20-30 & 2376 & $207(8.7)$ & 1 & & 1548 & $83(5.4)$ & 1 & \\
\hline$\geq 31$ & 718 & $47(6.6)$ & 0.73 (0.53 to 1.02$)$ & & 486 & $26(5.4)$ & $1.00(0.63$ to 1.57$)$ & \\
\hline \multicolumn{9}{|l|}{ Country } \\
\hline Benin & 1019 & 108 (10.6) & $1.37(1.01$ to 1.84$)$ & & 923 & $50(5.4)$ & 1 & \\
\hline Gabon & 929 & $119(12.8)$ & 1.70 (1.27 to 2.27$)$ & 0.0002 & 886 & $50(5.6)$ & $1.04(0.70$ to 1.56$)$ & 0.56 \\
\hline Mozambique & 1092 & $87(8.0)$ & 1 & & 982 & $64(6.5)$ & $1.21(0.83$ to 1.78$)$ & \\
\hline Tanzania & 1016 & 77 (7.6) & 0.95 (0.69 to 1.30$)$ & & NA & NA & NA & \\
\hline \multicolumn{9}{|l|}{ First ANC visit } \\
\hline First trimester & 292 & 35 (12.0) & 1.66 (1.08 to 2.55$)$ & & 224 & $16(7.1)$ & 1.51 (0.82 to 2.79$)$ & \\
\hline $\begin{array}{l}\text { Second } \\
\text { trimester }\end{array}$ & 2868 & $288(10.0)$ & 1.36 (1.03 to 1.79$)$ & 0.03 & 1865 & $114(6.1)$ & $1.28(0.86$ to 1.89$)$ & 0.33 \\
\hline Third trimester & 895 & $68(7.6)$ & 1 & & 701 & $34(4.8)$ & 1 & \\
\hline \multicolumn{9}{|l|}{ Parity } \\
\hline Nulliparous & 1314 & $182(13.8)$ & 1.95 (1.58 to 2.40$)$ & $<0.0001$ & 835 & $54(6.5)$ & 1.16 (0.83 to 1.62$)$ & 0.39 \\
\hline Multiparous & 2742 & $209(7.6)$ & 1 & & 1956 & $110(5.6)$ & 1 & \\
\hline \multicolumn{9}{|l|}{ BMI } \\
\hline Normal & 2663 & $264(9.9)$ & 1 & & 1620 & $117(6.1)$ & 1 & \\
\hline Underweight & 488 & $80(16.4)$ & 1.78 (1.35 to 2.33$)$ & $<0.0001$ & 372 & $24(6.4)$ & $1.06(0.67$ to 1.67$)$ & 0.39 \\
\hline $\begin{array}{l}\text { Overweight/ } \\
\text { obese }\end{array}$ & 902 & $47(5.2)$ & 0.50 (0.36 to 0.69$)$ & & 496 & $23(4.6)$ & 0.75 (0.47 to 1.18$)$ & \\
\hline \multicolumn{9}{|l|}{ MUAC (mm) } \\
\hline$\geq 240$ & 3277 & $272(8.3)$ & 1 & & 2199 & $128(5.8)$ & 1 & \\
\hline$<240$ & 767 & $119(15.5)$ & 2.03 (1.61 to 2.56$)$ & $<0.0001$ & 586 & $36(6.1)$ & $1.06(0.72$ to 1.55$)$ & 0.77 \\
\hline \multicolumn{9}{|c|}{$\mathrm{C}_{1}$} \\
\hline Literate & 2811 & $262(9.3)$ & 1 & & 1725 & $96(5.6)$ & 1 & \\
\hline Illiterate & 1245 & $129(10.4)$ & $1.12(0.90$ to 1.40$)$ & 0.33 & 1066 & $68(6.4)$ & $1.16(0.84$ to 1.59$)$ & 0.38 \\
\hline \multicolumn{9}{|c|}{ Plasmodial infection at delivery } \\
\hline No & 3682 & $344(9.3)$ & 1 & & 2580 & $1449(5.8)$ & 1 & \\
\hline Yes & 197 & $27(13.7)$ & 1.54 (1.01 to 2.35$)$ & 0.05 & 174 & $9(5.2)$ & $0.89(0.44$ to 1.78$)$ & 0.74 \\
\hline \multicolumn{9}{|c|}{ 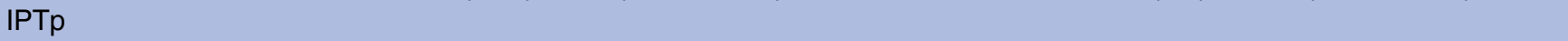 } \\
\hline MQ & 2686 & $260(9.7)$ & 1 & & 1845 & $111(6.0)$ & 1 & \\
\hline SP & 1370 & $131(9.6)$ & $0.99(0.79$ to 1.23$)$ & 0.9 & 946 & $53(5.6)$ & 0.93 (0.66 to 1.30$)$ & 0.66 \\
\hline \multicolumn{9}{|c|}{ Baseline anaemia } \\
\hline No & 1646 & $149(9.0)$ & 1 & & 1016 & $69(6.8)$ & 1 & \\
\hline Yes & 2396 & $242(10.1)$ & $1.13(0.91$ to 1.40$)$ & 0.4 & 1764 & $95(5.4)$ & 0.78 (0.57 to 1.08$)$ & 0.13 \\
\hline \multicolumn{9}{|l|}{ Syphilis test } \\
\hline Negative & 3921 & $379(9.7)$ & 1 & & 2723 & $156(5.7)$ & 1 & \\
\hline Positive & 55 & $5(9.1)$ & 0.93 (0.37 to 2.36$)$ & 0.88 & 39 & $5(12.8)$ & 2.42 (0.93 to 6.27$)$ & 0.103 \\
\hline
\end{tabular}

adolescent pregnancies may not be of similar public health importance in all sub-Saharan African countries. In countries with high proportions of young adolescent pregnancies, the establishment of dedicated antenatal care programmes may therefore be of comparatively higher public health importance to improve maternal, neonatal and adolescent health.

The major strengths of this study were its prospective design and the highly standardised data collection and follow-up of participants in diverse African sub-regions.
In addition, the setting of a randomised controlled trial ensured high coverage of standard antenatal care including vitamin and micronutrient supplementation, insecticide-treated bednets and availability of healthcare without access barriers. However, this analysis is not without limitations. Importantly, this study only included HIV negative pregnant women willing to participate in the main clinical trial, constituting a limitation for the external validity of this study. Furthermore, the interplay between risk factors for adverse pregnancy outcome is 
Table 3 Multivariate analysis of risk factors associated with low birth weight and preterm delivery

\begin{tabular}{|c|c|c|c|c|c|c|c|c|}
\hline Parameters & \multicolumn{4}{|l|}{ Birth weight } & \multicolumn{4}{|l|}{ Preterm birth } \\
\hline \multicolumn{9}{|c|}{ Maternal age (years) } \\
\hline $14-16$ & 2.06 (1.37 to 3.12$)$ & & 1.29 (0.81 to 2.06$)$ & & $1.73(1.01$ to 2.98$)$ & & $2.16(1.10$ to 4.24$)$ & \\
\hline 20-30 & 1 & & 1 & & 1 & & 1 & \\
\hline$\geq 31$ & $0.73(0.52$ to 1.03$)$ & & 0.85 (0.60 to 1.20$)$ & & $0.92(0.57$ to 1.49$)$ & & $0.88(0.51$ to 1.36$)$ & \\
\hline \multicolumn{9}{|c|}{$x^{2}$} \\
\hline \multicolumn{9}{|l|}{ Literacy } \\
\hline Literate & 1 & 0.80 & 1 & 0.17 & 1 & 0.14 & 1 & 0.11 \\
\hline Illiterate & $1.04(0.78$ to 1.38$)$ & & $1.23(0.91$ to 1.66$)$ & & 1.35 (0.91 to 2.01$)$ & & $1.43(0.94$ to 2.16$)$ & \\
\hline \multicolumn{9}{|c|}{ Baseline anaemia } \\
\hline No & & & & & 1 & 0.18 & 1 & 0.14 \\
\hline Yes & & & & & $0.80(0.57$ to 1.11$)$ & & $0.79(0.56$ to 1.10$)$ & \\
\hline Multiparous & 1 & & 1 & & 1 & & 1 & \\
\hline \multicolumn{9}{|l|}{ MUAC $(\mathrm{mm})$} \\
\hline$>240$ & 1 & $<0.0001$ & 1 & 0.05 & & & & \\
\hline$<240$ & $1.84(1.44$ to 2.36$)$ & & $1.32(1.00$ to 1.74$)$ & & & & & \\
\hline
\end{tabular}

*Adjusted for country, antenatal clinic; BMl: body mass index; MUAC: mid-upper arm circumference.

†Adjusted for country, first antenatal clinic visit, treatment group and infant gender.

ANC, antenatal clinic; BMI, body mass index; IPTp, intermittent preventive treatment of malaria in pregnancy; LRT, likelihood ratio; MQ, mefloquine; MUAC, mid-upper arm circumference;

$\mathrm{SP}$, sulfadoxine-pyrimethamine. 
complex and residual confounding may not be completely ruled out. To minimise this risk, multivariable analysis and restricted analysis of data have been performed, supporting the univariate findings.

In summary, this large prospective clinical trial provides conclusive evidence that young adolescent girls are at considerably higher risk for premature and low birth weight deliveries in sub-Saharan Africa. From a public health perspective, young adolescent pregnant women constitute an easily identifiable patient population amenable to targeted antenatal care programmes. Development of tailored antenatal care and facilitation of early attendance of antenatal care by young adolescent girls should therefore become a priority to improve adolescent health in sub-Saharan Africa.

\section{Author affiliations}

${ }^{1}$ Centre de Recherches Médicales de Lambaréné (CERMEL), Albert Schweitzer Hospital, Lambaréné, Gabon

${ }^{2}$ Institute of Tropical Medicine, University of Tübingen, Tübingen, Germany

${ }^{3}$ German Centre for Infection Research (DZIF), Tübingen, Germany

${ }^{4}$ Département de Parasitologie-Mycologie, Université des Sciences de la

Santé, Libreville, Gabon

${ }^{5}$ Leiden University Medical Centre (LUMC), Leiden, The Netherlands

${ }^{6}$ ManhiçaHealthResearch Center (CISM), Manhiça, Mozambique

${ }^{7}$ ISGlobal, Barcelona Ctr. Int. Health Res. (CRESIB), Hospital Clínic-

Universitat de Barcelona, Barcelona, Spain

${ }^{8}$ Faculté de Sciences de la Santé, Université Abomey Calavi, Cotonou, Benin

${ }^{9}$ Institut pour la Recherche et le Développement (IRD), Paris, France

${ }^{10}$ Ifakara Health Institute, Dodoma, Tanzania

${ }^{11}$ Ngounie Medical Research Centre, Fougamou, Gabon

${ }^{12}$ Department of Medicine I, Division of Infectious Diseases and Tropical

Medicine, Medical University of Vienna, Vienna, Austria

Acknowledgements The authors are thankful to participants and the respective staff of the MiPPAD study from Barcelona, Benin, Gabon, Mozambique and Tanzania.

Contributors GM-N and MR conceived the study. GM-N analysed the data and drafted the manuscript. MC, RG, PGK, MY, AAA, JJA, CM and MiR reviewed all aspects of the study design and analysis and contributed to the drafting of the manuscript. JRM, RZM, AB, P-BM, SO, AM, EM, RG, AM, STA and GM-N collected the data and contributed to the data analysis and drafting of the manuscript. All authors approved the final version of the manuscript.

Funding This study was funded by the European Developing Countries Clinical Trials Partnership (EDCTP; IP.2007.31080.002), the Malaria in Pregnancy Consortium and the following national agencies: Instituto de Salud Carlos III (PI08/0564), Spain; Federal Ministry of Education and Research (BMBF FKZ: da01KA0803), Germany; Institut de Recherche pour le Développement (IRD), France and the Karl Landsteiner Gesellschaft. The analysis of this substudy was funded by the Federal Ministry of Science, Research and Economy of Austria as part of the EDCTP-2 programme. This study is part of the EDCTP2 programme supported by the European Union. We acknowledge support by Deutsche Forschungsgemeinschft and Open Access Publishing fund of University Tuebingen.

Competing interests None declared.

Ethics approval The MiPPAD study protocol and study materials received ethical approvals from the University Hospital of Barcelona Institutional Review Board and from national ethics committees of each African site.

Provenance and peer review Not commissioned; externally peer reviewed.

Data sharing statement No additional data are available.

Open Access This is an Open Access article distributed in accordance with the Creative Commons Attribution Non Commercial (CC BY-NC 4.0) license, which permits others to distribute, remix, adapt, build upon this work noncommercially, and license their derivative works on different terms, provided the original work is properly cited and the use is non-commercial. See: http:// creativecommons.org/licenses/by-nc/4.0/

\section{REFERENCES}

1. WHO. Maternal and perinatal health. WHO (cited 30 August 2013). http://www.who.int/reproductivehealth/publications/maternal perinatal_health/en/

2. Kinney MV, Kerber KJ, Black RE, et al. Sub-Saharan Africa's mothers, newborns, and children: where and why do they die? PLOS Med 2010;7:e1000294.

3. Adegnika AA, Verweij JJ, Agnandji ST, et al. Microscopic and sub-microscopic Plasmodium falciparum infection, but not inflammation caused by infection, is associated with low birth weight. Am J Trop Med Hyg 2006;75:798-803.

4. Ramharter M, Grobusch MP, Kiessling G, et al. Clinical and parasitological characteristics of puerperal malaria. J Infect Dis 2005;191:1005-9.

5. Darmstadt GL, Bhutta ZA, Cousens S, et al. Evidence-based, cost-effective interventions: how many newborn babies can we save? Lancet 2005;365:977-88.

6. Friberg IK, Kinney MV, Lawn JE, et al. Sub-Saharan Africa's mothers, newborns, and children: how many lives could be saved with targeted health interventions? PLoS Med 2010;7: e1000295.

7. Ramharter M, Schuster K, Bouyou-Akotet MK, et al. Malaria in pregnancy before and after the implementation of a national IPTp program in Gabon. Am J Trop Med Hyg 2007;77: 418-22.

8. Ramharter M, Chai SK, Adegnika AA, et al. Shared breastfeeding in central Africa. AIDS Lond Engl 2004:18:1847-9.

9. Kramer MS, Zhang X, Platt RW. Analyzing risks of adverse pregnancy outcomes. Am J Epidemiol 2014;179:361-7.

10. Lori S. Ashford. AFRICA'S YOUTHFUL POPULATION: RISK OR OPPORTUNITY? 2007. http://www.sarpn.org/documents/d0002763/ PRB_Africa_youth_Jun2007.pdf

11. Sexual health and rights of adolescents: a dialogue with sub-Saharan Africa (cited 19 April 2015). http://www.academia.edu/ $10977260 /$ Sexual health and rights of adolescents A dialogue with_sub-Saharan_Africa

12. González R, Mombo-Ngoma G, Ouédraogo S, et al. Intermittent preventive treatment of malaria in pregnancy with mefloquine in HIV-negative women: a multicentre randomized controlled trial. PLoS Med 2014;11:e1001733.

13. WHO. Physical status: the use and interpretation of anthropometry Report of a WHO Expert Committee. Technical Report Series No. 854. WHO (cited 29 August 2013). http://www.who.int/childgrowth/ publications/physical_status/en/

14. WHO. Adolescent pregnancy. WHO (cited 30 August 2013). http:// www.who.int/maternal_child_adolescent/topics/maternal/adolescent pregnancy/en/index.html

15. Greenwood AM, Armstrong JR, Byass P, et al. Malaria chemoprophylaxis, birth weight and child survival. Trans $R$ Soc Trop Med Hyg 1992;86:483-5.

16. Sasidharan K, Dutta S, Narang A. Validity of New Ballard Score until 7th day of postnatal life in moderately preterm neonates. Arch Dis Child Fetal Neonatal Ed 2009;94:F39-44.

17. Kleinbaum DG, Klein M. Logistic regression. New York, NY: Springer New York, 2010 (cited 4 July 2015). http://link.springer.com/

18. Kramer MS. Intrauterine growth and gestational duration determinants. Pediatrics 1987;80:502-11.

19. Kramer MS. The epidemiology of adverse pregnancy outcomes: an overview. J Nutr 2003;133:1592S-6S.

20. Aras R. Is maternal age risk factor for low birth weight? Arch Med Health Sci 2013;1:33-7.

21. Chen $\mathrm{X}-\mathrm{K}$, Wen SW, Fleming $\mathrm{N}$, et al. Teenage pregnancy and adverse birth outcomes: a large population based retrospective cohort study. Int J Epidemiol 2007;36:368-73.

22. Strobino DM, Ensminger ME, Kim YJ, et al. Mechanisms for maternal age differences in birth weight. $A m \mathrm{~J}$ Epidemiol 1995;142:504-14.

23. Guyatt HL, Snow RW. Impact of malaria during pregnancy on low birth weight in sub-Saharan Africa. Clin Microbiol Rev 2004:17:760-9.

24. Desai M, ter Kuile FO, Nosten F, et al. Epidemiology and burden of malaria in pregnancy. Lancet Infect Dis 2007;7:93-104. 